\title{
IDENTIDADES JUDAICAS: \\ As Comunidades de Conversão na Serra Gaúcha
}

JEWISH IDENTITIES: CONVERSION COMMUNITIES IN THE SERRA GAÚCHA

Cristine Fortes Lia

\begin{abstract}
RESUMO
A pluralidade religiosa brasileira vem crescendo significativamente nas últimas décadas. A busca por identificação com uma corrente religiosa promove um processo de migração religiosa e de consolidação de novas organizações de fé. Este estudo analisa uma comunidade religiosa, fundada na cidade de Caxias do Sul, na Serra Gaúcha, que manifesta a fé no judaísmo. Por meio de uma trajetória de conversões marcada por especificidades, este grupo passou a se considerar judeu em uma cidade marcada pelas manifestações católicas. $\mathrm{O}$ anseio por uma identidade judaica caracteriza a experiência histórica desta comunidade.
\end{abstract}

Palavras-Chave: Religiosidades. Judaísmo. Identidade. História.

\begin{abstract}
Brazilian religious plurality has been growing significantly in recent decades. The search for identification with a current religious promotes a process of religious migration and consolidation of new faith organizations. This study analyzes a religious community founded in the city of Caxias do Sul, in the Serra Gaúcha, which manifests its faith in Judaism. By means of a trajectory of conversions marked by specificities, this group happened to consider itself Jewish in a city marked by the catholic manifestations. The longing for a Jewish identity characterizes the historical experience of this community.
\end{abstract}

KEYWORDS: Religiousness. Judaism. Identit. History

\section{CONSIDERAÇÕES INICIAIS}

O censo de $2010^{1}$ revelou aspectos do cotidiano religioso da população brasileira. Alguns dos dados trazidos pelo censo evidenciaram a pluralidade religiosa e os constantes processos de migração religiosa no Brasil. Identificou, também, o crescimento de alguns grupos religiosos - como os pentecostais -, com um aumento do número dos que se declararam sem religião - sem ser ateus -, e o declínio de igrejas tradicionais.

Também trouxe dados sobre as comunidades judaicas no Brasil: segundo os números da pesquisa do IBGE, os judeus somariam 107 mil indivíduos. Apesar de constituírem um grupo numericamente pequeno dado os aproximadamente 200 milhões de brasileiros, os adeptos do judaísmo teriam apresentado crescimento quantitativo, se comparados aos dados das décadas anteriores. Em 2000, por

\footnotetext{
Doutora em História. Professora e pesquisadora do Programa de Pós-Graduação em História e do Curso de História da Universidade de Caxias do Sul - UCS. Editora da Revista Métis da Universidade de Caxias do Sul. E-mail: crisflia@bol.com.br

${ }^{1}$ Os dados do Censo de 2010 sobre as religiões no Brasil foram divulgados em 2012 pelo Instituto Brasileiro de Geografia e Estatística - IBGE. Neste estudo, as análises utilizadas são provenientes da obra "Religiões em movimento: o censo de 2010", organizada por Faustino Teixeira e Renata Menezes (2013).
} 
exemplo, os judeus somavam 87 mil fieis e, em 2010, 107 mil, evidenciando um aumento de 20 mil pessoas em uma década.

Os números apresentados pelo censo de 2010 sobre o judaísmo merecem ser analisados por meio de algumas especificidades, pois não se caracterizando como uma religião de proselitismo, o que justificaria esse aumento do número de adeptos? Destaca-se, ainda, que a taxa de natalidade da comunidade judaica não é expressiva. Grin e Gherman (2013), explicam que, nas últimas décadas, alguns fatores contribuíram para o crescimento da comunidade judaica, dentre os quais destacam uma mobilidade interna dentro do próprio grupo. Assim, por meio desse processo, judeus "não praticantes" estariam retornando às práticas religiosas.

Da mesma forma, os autores acima citados identificam um aumento de conversões por meio de casamentos mistos, com a consequente conversão de um dos cônjuges. Pequenas ondas migratórias recentes e a diversidade de correntes judaicas instaladas no Brasil corroboram para ampliar os números identificados pelo censo. A experiência cultural também permite que adeptos do judaísmo se identifiquem com a comunidade, independentemente das práticas religiosas.

Vejamos então as dificuldades de se compreender as complexas facetas do judaísmo brasileiro que, mesmo referido como religião em série histórica de censos desde 1940, não pode ser tomado apenas pela rubrica religiosa, ou seja, os que se definem "adeptos do judaísmo" não podem ser considerados judeus exclusivamente pelas suas práticas religiosas. Um dos mais importantes aspectos a ser ressaltado é que aqueles que se declaram judeus, quando respondem ao Censo, não são necessariamente "praticantes do judaísmo". Em uma escala, estes podem ser desde praticantes mais ou menos fervorosos dos preceitos da religião judaica até judeus fortemente seculares, e mesmo ateus, cuja definição identitária encontra-se ora na cultura, ora na etnicidade, ora na identificação do povo judeu. (GRIN, GHERMAN, 2013, p. 286).

A questão da identidade judaica se constrói de forma imperativa para a compreensão de toda e qualquer análise da comunidade. Nenhuma estatística explica o fenômeno do judaísmo se não estiver associada à resposta da ideia do "que é ser judeu”. O pertencimento à comunidade não se consolida por mera opção religiosa. "Se, para um olhar exterior, os judeus são definidos basicamente como membros de um grupo religioso, internamente prevalecem inúmeras modalidades de autopercepção e coesão grupal”. (SORJ, 1997, p. 59).

No século XXI, um processo religioso aparece na mídia: comunidades judaicas de autoconversão ${ }^{2}$. Com fieis de origem majoritariamente cristã, esses grupos se organizam em torno da fé no judaísmo. Constituem-se como "instituições" de caráter

2 Utiliza-se aqui a expressão autoconversão por se tratar de comunidades que não alcançaram a conversão por meios tradicionais. Sua inserção na vida religiosa judaica aconteceu por diferentes motivações, sem acompanhamento de rabinos, nem autorização de autoridades religiosas de Israel. 
local, com lideranças desvinculadas das comunidades tradicionais. Por meio de pregação e divulgação por sites, atraem novos membros.

Este estudo centra-se na "comunidade judaica" de Caxias do Sul, cidade predominantemente católica, localizada na Serra Gaúcha. Por meio de material divulgado pela mídia e por depoimentos coletados junto aos fieis da mesma, busca compreender o processo histórico de instalação dessa unidade religiosa, seus mecanismos de atração de adeptos e sua permanência e desestruturação.

Esses depoimentos aparecem no texto de forma anônima, pelo fato dos entrevistados ainda estarem em busca do seu elo religioso com o judaísmo, preparando-se para se inserir em outras comunidades. Assim, acredita-se que a divulgação dos nomes, neste momento, poderia comprometer alguns processos de conversão e/ou a condição de liderança comunitária de alguns depoentes. Destaca-se que todas as entrevistas estão autorizadas, pelos devidos termos de cessão, para uso nesta pesquisa 3 .

A história oral de pessoas anônimas ainda é bastante criticada, mas indispensável em determinadas circunstâncias de pesquisa. Segundo Meihy e Ribeiro (2011), em situações nas quais o depoente precisa ser preservado, pode-se omitir ou mudar o nome da pessoa. "Há casos em que se torna necessário, inclusive, alterar situações da história, do contexto ou da versão de algum fato capaz de possibilitar a precisão dos casos" (MEIHY; RIBEIRO, 2011, p. 116).

Neste artigo são utilizadas cinco entrevistas, sendo de quatro homens e de uma mulher, que foram coletadas no período de março a agosto de 2017; estas apresentam uma fala comum sobre o desenvolvimento da comunidade analisada. Como visa promover a discussão sobre um assunto específico, foi usada a história oral temática, com a orientação do entrevistado sobre o assunto abordado. Foram tomados os cuidados para não negligenciar a percepção do depoente, nem induzi-lo a fazer afirmações.

Como os trabalhos de história oral temática se dispõem a discussão em torno de um assunto central definido - mesmo que outros decorram ou concorram para seu esclarecimento -, os aspectos subjetivos ficam limitados ainda que não anulados. A presença do colaborador que entrevista deve ser atuante no sentido de favorecer a apresentação de argumentos do colaborador que responde a estímulos dados. $\mathrm{O}$ entrevistador, no caso de história oral temática, deve ser preparado antes com instruções sobre o assunto abordado. Quanto mais informações se têm previamente,

\footnotetext{
3 Este estudo é parte de uma pesquisa realizada junto à Universidade de Caxias do Sul, que aborda a diversidade religiosa na cidade da Serra Gaúcha. Atua como bolsista de iniciação científica a acadêmica Franciele de Almeida de Oliveira. As entrevistas estão arquivadas no acervo pessoal da pesquisadora e atingirão o domínio público no final do projeto, mantendo-se o anonimato dos depoentes. As mesmas ainda estão sendo realizadas, o que respalda a necessidade de anonimato nesse momento. Destaca-se ainda que no termo de cessão da entrevista fica expresso que a colaboração do entrevistado ficará anônima e foi realizada por meio de entrevista semiestruturada.
} 
mais interessantes e profundas podem ser suas questões. Conhecer as versões opostas, os detalhes menos revelados e até imaginar situações que mereçam ser questionadas é parte da preparação de roteiros investigativos. (MEIHY; HOLANDA, 2017, p. 39)

Utiliza-se, também, a história oral híbrida, já que a fala dos depoentes dialoga com outros tipos de fontes, em especial com a imprensa. "Preza-se o poder de conversa, contatos ou diálogos com outros documentos, sejam iconográficos ou escritos como: historiográficos, filosóficos ou literários. [...] valoriza-se a polifonia e reafirma-se que a história oral é social na medida em junta vozes dissonantes" (MEIHY; HOLANDA, 2017, p. 129).

Destaca-se que os depoimentos orais permitem ao historiador ampliar ainda mais essa sensibilidade para a compreensão do passado, através deles é possível identificar o que a memória selecionou: as falhas, os esquecimentos, as omissões, o que vem sendo lembrando pouco a pouco ao longo do depoimento, permitindo identificar as marcas que o passado realizou sobre a história do depoente. Como observa Costa (2001), a narrativa oral pode ser entendida como um "espaço privilegiado de sentimentos" (COSTA, 2001, p. 78). Assim, o ouvinte tem acesso a um tipo muito especial de fonte, que encontra tanto nas palavras, como nos silêncios, expressões de um tempo vivido no passado, que traduzido através das emoções nos narradores, fornece ao historiador não apenas os acontecimentos vividos, mas as expectativas, as frustrações, as decepções, as angústias, etc.

Mas o único e precioso elemento que as fontes orais têm sobre o historiador, e que nenhuma outra fonte possui em medida igual, é a subjetividade do expositor. Se a aproximação para a busca é suficientemente ampla e articulada, uma secção contrária da subjetividade de um grupo ou classe pode emergir. Fontes orais contam-nos não apenas o que o povo fez, mas o que queria fazer, o que acreditava estar fazendo e o que agora pensa que fez. Fontes orais podem não adicionar muito ao que sabemos, por exemplo, o custo material de uma greve para os trabalhadores envolvidos; mas contanos bastante sobre os seus custos psicológicos. (PORTELLI, 1997, p. 30).

Dessa forma, o depoimento oral nos revela, algumas vezes, muito mais através de seus silêncios e esquecimentos, do que pelas suas palavras; o indizível é sempre muito revelador. É possível evidenciar medos e angústias que se transportam do passado para o presente, visíveis nos gestos e nas lágrimas, bem como nas alegrias e saudades caracterizadas pelos sorrisos, pelas ênfases e pelas expressões de satisfação em poder reproduzir o que o tempo já afastara. (LIA, 2004).

Da mesma maneira, a utilização da imprensa também mereceu cuidados. O texto jornalístico precisa ser analisado sob a luz de que corresponde a uma fonte de caráter não acadêmico, que visa promover e vender uma determinada ideia. Elmir (1995) chama a atenção sobre a importância e os cuidados necessários para a utilização da imprensa como fonte histórica. É preciso considerar a frequência com que o tema foi 
abordado, a subjetividade dos elaboradores dos textos, a recepção dos mesmos na sociedade da época, o método de leitura adotado pelo historiador e a necessidade de confrontação com outras fontes documentais e bibliográficas.

O jornal jamais pode ser visto como um dado, a partir do qual abstraímos os elementos de uma suposta realidade. O jornal, como um conjunto de páginas, é o receptáculo de textos que exigem de nós uma leitura diferente daquela que fazemos ao pegar o Correio do Povo, a Zero Hora, ou a Folha de São Paulo, todos os dias em nossa porta. Quando saímos de casa e nos deslocamos para cá, é um outro leitor que surge. Não o leitor do Correio, da Zero ou da Folha, mas o leitor de um jornal que já não circula mais, um jornal que, materialmente, está deslocado no tempo e no espaço. [...]. Eu quero dizer com isto que devemos fazer uma "leitura intensiva" destes jornais e não uma "leitura extensiva”. Ler os jornais extensivamente é o que fazemos diariamente hoje. Ler intensivamente é o que acontece com leitores cujo tempo da experiência da leitura não corresponde ao tempo da formulação do jornal (ELMIR, 1995, p. 21-22).

Além disso, precisa-se ter muita cautela para não iniciar a análise dos periódicos com conclusões ou generalizações já determinadas, utilizando-os apenas para reforçar crenças anteriores à própria pesquisa. "Quer dizer, o resultado da pesquisa está previamente definido pelos preconceitos de quem a faz" (ELMIR, 1995, p. 24).

\section{JUDEUS E JUDAÍSMO, DEFINIÇÕES E CONCEITOS}

Para melhor compreender o fenômeno do judaísmo 4, trabalha-se com o conceito de etnia, que funda sua definição em uma base cultural, definindo o grupo humano estudado por meio de suas tradições culturais. Um grupo étnico se constitui pela manutenção de traços culturais. Como diz Manuela Carneiro da Cunha (1987): "Grupo étnico seria, então, aquele que compartilha valores, formas e expressões culturais" (CUNHA, 1987, p. 114-115).

Cultura precisa ser compreendida como algo dinâmico, capaz de se reelaborar através do tempo, sofrendo as influências do espaço em que está inserida. Ela compreende as mais diversas manifestações dos grupos humanos. Por seu dinamismo, a cultura permite que as características dos grupos étnicos se reelaborem conforme as necessidades, ou seja, um grupo pode adaptar seus traços culturais a uma determinada realidade, sem que com isso perca seus elos, seus pontos de distinção em relação a outros grupos, o que leva a uma compreensão dinâmica do próprio conceito de etnia.

Esses pontos de distinção, essa tradição cultural que cada grupo étnico compartilha, constitui sua identidade: a sua forma de serem iguais entre si e distintos em relação aos outros grupos. As identidades étnicas são as formas de identificações

\footnotetext{
4 Parte da discussão teórica aqui apresentada encontra-se na Tese de Doutorado Bons cidadãos: $a$ comunidade judaica do Rio Grande do Sul durante o Estado Novo (1937-1945) (LIA, 2004).
} 
dos grupos humanos, identificam não apenas as semelhanças dentro do grupo, como permitem reconhecer sua diferença em relação aos outros, e a dos outros em relação a ele.

Em geral, as identidades étnicas operam na busca das diferenças. Na dificuldade em definir seu próprio grupo, busca sua caracterização na sua diferença em relação ao outro. A sua identidade constitui-se na negação do outro. E o direito de ser diferente tem sido um dos debates mais intensos dos últimos tempos: políticos e intelectuais têm buscado uma democracia que garanta não apenas o direito de ser igual, mas principalmente de ser diferente.

A maior parte das ideias sobre judaísmo está vinculada a visões estereotipadas sobre o "ser judeu". Pertencer à comunidade judaica adquiriu a conotação de ser errante, negociante, sovina, larápio, usurário. O médico e escritor Moacyr Scliar (1990b) em seu texto cita os diversos mitos que se constroem em torno do judaísmo: o mito do usurário judeu, do capital judaico internacional, do revolucionário judeu, da ciência judaica... A maioria desses mitos corresponde, segundo Scliar (1990b), a fatos históricos que podem ser explicados, como, por exemplo, o mito do judeu usurário que "[...] escamoteia o fato de que, no mundo feudal, o empréstimo de dinheiro a juros era vedado aos cristãos" (SCLIAR, 1990b, p. 83).

John Dominic Crossan (1995) faz uma distinção entre dois tipos de preconceitos: o antissemitismo e o antijudaísmo. Segundo o autor: "[...] o anti-semitismo só aparece na história quando o antijudaísmo está combinado com racismo" (CROSSAN, 1995, p. 47). O antijudaísmo é considerado por Crossan como o preconceito religioso, podendo o judeu convertido se afastar dele; já o antissemitismo está ligado à questão étnica, não sendo possível o judeu dele se afastar.

A definição mais comum do judaísmo está ligada à religiosidade do grupo. Nesse caso, a crença na religião judaica, ou seja, o fator religioso, é base de organização do grupo. Essa visão, no entanto, parece insuficiente, no século XXI, para definir o fenômeno do judaísmo. "Por outro lado, a identidade judaica não se esgota nos limites da religião e a sua complexidade é de tal ordem que qualquer tentativa de definição rígida da identidade empobrece suas ricas formas de manifestação" (GRIN, GHERMAN, 2013, p. 283-284).

Os judeus constituem um grupo étnico, que tem como base uma história comum (do judaísmo). A ideia de história comum possibilita uma visão mais ampla do conceito de judaísmo. Assim, a conversão religiosa não é fator suficientemente forte para inserir alguém no mundo judeu ou, ao contrário, excluí-lo dele. O ingresso à comunidade pode se dar via conversão, mas o que se questiona é até onde o converso tornou-se um judeu. Um ateu não pode ser judeu? Sigmund Freud não era judeu? Olga Benário Prestes era comunista e, portanto, ateia. Entretanto, sabe-se que ela foi 
deportada para a Alemanha nazista e enviada para um campo de concentração, onde morreu durante a Segunda Guerra Mundial, por ser judia.

Quando John Dominic Crossan (1995) faz sua distinção entre antijudaísmo e antissemitismo, se observa que o abandono da religião não inibe o antissemitismo, pois este estaria ligado à etnia, não definida meramente pelo fator religioso. A ideia de história comum baseia-se na forte ligação do judaísmo com sua própria história. Um vínculo que não se estabelece apenas por se manterem as tradições do passado, mas pelo fato de cada indivíduo estar envolvido com a história judaica como sua própria história de vida. Todas as formas de sobrevivência que o grupo desenvolveu, suas múltiplas táticas de resistência e os mitos que delas se originaram, constituem o universo de todos os judeus, em qualquer lugar do mundo.

Segundo Moacyr Scliar (1990b), algumas situações de desespero propiciam o aparecimento de mitos na tradição judaica, como o do Golem, a criatura gigantesca responsável pela defesa dos judeus de seus inimigos. Essa lenda judaica revela muitas das características que configuram o judaísmo: o Golem é o salvador de um povo amedrontado, "[...] nosso perseguido e assassinado e ainda assim imortal povo" (WIESEL, 1986, p. 13).

O humor judaico, de forma irônica e absurda, remonta às tradições desse grupo, através da observação de uma identidade que se firma diante das adversidades, das lutas, das inúmeras tentativas de sobrevivência e, também, pela capacidade de adaptar-se a qualquer situação por mais absurda que a mesma represente:

O mundo vai sofrer por um novo dilúvio. Dentro de três dias, as águas cobrirão a face da Terra. O líder budista vai à TV e pede que todos se convertam ao Budismo, para assim obter a salvação e acesso ao céu. O Papa aparece na TV com mensagem semelhante: "Todavia estão em tempo de aceitar Jesus".

O grão-rabino de Israel, por seu lado, também comparece à TV, trazendo, no entanto, mensagem um tanto diferente: "Judeus, temos três dias para aprender a viver debaixo d'água“" (SCLIAR, 1990a, p. 202).

São essas formas de resistência, de adaptar-se, de viver, que extrapolam a esfera religiosa, que constituem a história judaica e a caracterizam. E é este vínculo com essa história que define o grupo judaico. A história de uma nação que sobreviveu durante séculos sem um território, e que mesmo espalhada pelo mundo, não perdeu sua identidade. A lógica da sobrevivência também é uma marca importante do judaísmo, pois, apesar de todas as perseguições, de todas as estratégias de aniquilação, os judeus sobrevivem e se mantêm unidos.

É esse vínculo, essa ideia de que a história de qualquer judeu, em qualquer lugar do mundo, em qualquer tempo, constitui a história de todos os judeus e a de cada um, que não se adquire pelo simples ato da conversão, da adoção da nova religião. Nem se perde quando a conversão se dá ao contrário. A fé na religião judaica é apenas um dos 270 
muitos aspectos culturais que definem o judaísmo.

Agnóstico ou ateu, o judeu que se inscreve em sua comunidade participa, pois, de um rito que exprime a fé ou, mais simplesmente - laicamente -, celebra a vitalidade do grupo outra vez reunido [...] Mas a distinção essencial se mantém: o judeu que perdeu a fé, que deixou de ser praticante, continua a ser judeu, para si e para os outros (SIMONNAHUM, 1992, p. 464).

A identidade judaica também se constitui em resposta às necessidades de assimilação à sociedade local, já que se estabelece, majoritariamente, como uma cultura imigrante. Sorj (1997) identifica que as identidades dos judeus na contemporaneidade se constituíram "em cima de um esforço auto-reflexivo e como resposta ao anti-semitismo" (SORJ, 1997, p. 20). Na sociedade brasileira contemporânea, o preconceito contra os judeus seria, para esse autor, menor ao praticado em outras regiões, promovendo a constituição de outro tipo de identidade.

Além disso, no Brasil os "estrangeiros", em especial europeus, seriam vistos de forma positiva, como sinônimo de desenvolvimento, permitindo a manutenção de elementos culturais dos mesmos. Outro aspecto relevante sobre a identidade dos judeus brasileiros centra-se na crença de que constituiriam um grupo homogêneo e bem sucedido em níveis culturais e econômicos, o que possibilita uma aceitação cultural do grupo.

O perfil sociológico dos adeptos do judaísmo, conforme o Censo de 2010, confirma, ademais, o que já se observava em censos anteriores: os judeus se concentram em grandes centros urbanos, possuem alta escolaridade, renda per capita bem acima da média e um dos maiores índices de Desenvolvimento Humano (IDH) do Brasil. De modo geral, são brancos, de origem europeia e com formação superior. (GRIN, GHERMAN, 2013, p. 285-286).

No entanto, essas homogeneidades não podem ser vistas de forma unificadora da comunidade judaica. As identidades culturais e religiosas do grupo são bastante diversas, identificando a dinâmica do mesmo. Distintas vertentes da religião judaica estão presentes no Brasil, desde as mais conservadoras até as mais reformistas, sendo, também, possível viver o judaísmo apenas por meio do vínculo cultural, não religioso, revelando as inúmeras formas de ser judeu no Brasil. E, retomando a ideia de que os elos com a comunidade judaica remetem a história comum:

Finalmente, no momento atual, chamado por alguns de pós-modernidade, mudanças radicais nos estilos identitários seculares vêm ocorrendo. A identificação com ideologias coerentes e exclusivas vem sendo substituída por um movimento, que, aliás, não ocorre exclusivamente entre judeus, de recuperação e recriação da tradição. Depurados de seus contextos de origem, de carga de emoções e sentimentos que provocaram, das hostilidades e inimizades que instauraram, das vitórias e derrotas que sofreram, estas manifestações aparecem hoje como parte de um passado idealizado. Cultivar ligações com o judaísmo significa, na atualidade, consumir um ou outro 
produto cultural de um vasto cardápio de bens simbólicos. Estes podem se expressar, por exemplo, na participação em festas e rituais religiosos; no consumo habitual de comida judaica adquirida em delicatessen da moda; na realização de viagens regulares a Israel; no consumo de bens culturais produzidos sobre o Holocausto, como bestsellers, filmes, exposições, memórias, viagens guiadas aos campos de extermínio; na produção de arquivos, bancos de dados, museus, multimídias sobre a história das comunidades judaicas antes e depois da grande emigração europeia moderna, etc. (SORJ, 1997, p. 68-69).

O entendimento sobre o conceito de judaísmo passa, necessariamente, pela compreensão do vínculo histórico com a comunidade. Sorj (1997) observa que o estudo da história judaica é um dos primeiros passos para um processo de conversão, pois propicia uma compreensão ampla do judaísmo. Assim, pode-se dizer que ser judeu é partilhar de uma história comum e, na maior parte das vezes, professar a fé no judaísmo.

\section{A congregaÇão Nova Aliança de CaXias do Sul}

Na edição de 4 e 5 de fevereiro de 2012, o Jornal Pioneiro 5 realizou uma matéria especial, intitulada "Louvor de sábado" 6, na qual descrevia a comunidade, considerada judaica pelos seus fieis, chamada Nova Aliança. A sede da mesma funcionava em uma casa simples do bairro Serrano e contava, na data da publicação, com um número de 50 membros. Suas práticas religiosas eram orientadas por Elazar Bem Elisha. O Jornal Pioneiro noticiou (por meio de um texto dividido em várias sessões temáticas, com títulos como "Uma ilha no tempo", "Mandamentos", "Questão de princípios", “A conversão", "Gastronomia Kosher" e "Leis dietéticas”) as formas de viver de um grupo que, segundo o periódico, mesmo sem ter ascendência judaica, decidiu seguir o judaísmo enquanto religião.

Em pequenos "boxes", a matéria também trazia informações sobre a história do judaísmo e da imigração judaica no sul do Brasil. O foco estava, no entanto, em evidenciar as particularidades de ser um seguidor do judaísmo em Caxias do Sul. Destacava as tensões nas relações de trabalho (pelo respeito ao sábado), o uso de véu e o quipá, bem como a exigência de uma postura mais discreta na estética dos integrantes da comunidade, que se considera judaica, na cidade marcada pelo catolicismo.

\footnotetext{
5 O Jornal Pioneiro circula desde 1948 e hoje está presente em 64 municípios da região de Caxias do Sul. Desde 1993 integra a rede de jornais do Grupo RBS. Em 2008 ganhou o site pioneiro.com e edição on line.

${ }^{6}$ A referida matéria do Jornal Pioneiro foi redigida pela jornalista Fernanda Fedrizzi. Ocupou cinco páginas da edição física do periódico, com textos das falas dos fieis e imagens. No dia anterior, 03 de fevereiro de 2012, a edição on line do Pioneiro promoveu a mesma matéria, inserindo comentários da historiadora Cristine Fortes Lia e do rabino Mendel, responsável pela Sinagoga Beit Lubavitch, de Porto Alegre. (PIONEIRO, 2017).
} 
A cidade de Caxias do Sul se localiza na Serra Gaúcha, região marcada pela forte presença de indivíduos com ascendência italiana, que professam o catolicismo. Ao longo da trajetória histórica do município não foram consolidados grupos praticantes do judaísmo tradicional 7.

O município de Caxias do Sul está localizado na região nordeste do Estado do Rio Grande do Sul, no sul do Brasil. A partir da segunda metade do século XIX, teve início o processo de ocupação do território por imigrantes europeus, sobretudo, originários da Península Itálica. A imigração teve o incentivo do governo imperial, que se preocupou em criar uma infraestrutura para receber os estrangeiros. Uma das primeiras medidas adotadas foi a criação de colônias, divididas em pequenos lotes que eram concedidos aos colonos para o desenvolvimento da agricultura e a ocupação territorial. (LIA; RADÜNZ, 2017, p. 426).

O processo de ocupação das colônias gerou uma identidade para a região, bastante associada à italianidade e ao catolicismo. "Esse crescimento demográfico com imigrantes italianos significou também uma presença católica majoritária” (LIA, RADÜNZ, 2017 p. 427). A coesão e o status social se consolidaram por meio do catolicismo. "Como o maior fluxo de imigrantes se deu com colonos da Itália, a presença católica foi uma decorrência natural. A historiografia da imigração tem ressaltado a importância dos elementos religiosos católicos para a coesão social" (LIA, RADÜNZ, 2017, p. 427).

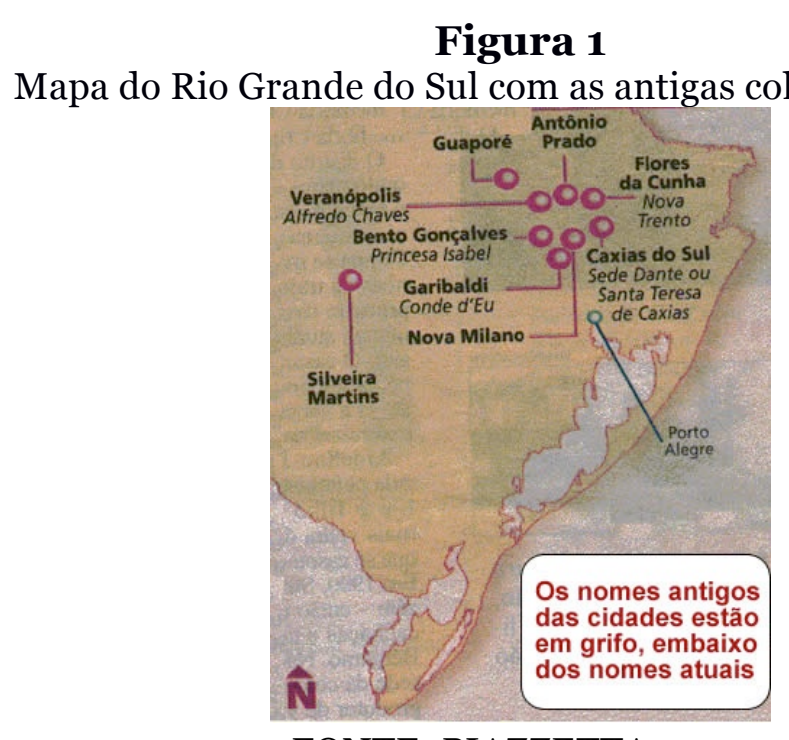

FONTE: PIAZZETTA, 2017

7 Considera-se como judaísmo tradicional e/ou instituições judaicas tradicionais as práticas estabelecidas por grupos que são reconhecidos como judeus por autoridades religiosas. Para o indivíduo ser parte da comunidade religiosa precisa passar pelos ritos religiosos obrigatórios, realizados perante uma autoridade religiosa, com devida formação. Lideranças religiosas do judaísmo não reconhecem fieis que não tenham sido incorporados ao grupo de forma tradicional. Nem líderes religiosos sem formação. Tampouco templos sem a organização estabelecida pelos preceitos religiosos do judaísmo. 
A maior identificação com o catolicismo não pode ser pensada como forma de homogeneidade cultural. Outras matrizes religiosas se estabeleceram na cidade, em especial a matriz africana, fazendo com que Caxias do Sul esteja entre os municípios com o maior número de adeptos das religiões afro-brasileiras. Ainda possui comunidades protestantes, pentecostais e muçulmanas. Dentre os adeptos do Islã, existe a comunidade fundada pelos palestinos por volta dos anos de 1980 e um grupo mais recente, constituído pelos senegaleses.

Assim, o grupo da Nova Aliança se organizou sem contato com outras comunidades judaicas locais. O vínculo de fundação se deu por meio do acesso a outra instituição com o mesmo nome, que hoje tem sede no Paraná: a Congregação Israelita Nova Aliança (doravante denominada CINA). Esta tem sua "sinagoga" sede em Curitiba e pode ser facilmente identificada por meio do site da mesma. Nesse espaço o grupo se apresenta, doutrina e recebe doações. No link "Quem Somos" do site oficial da CINA (2017), fazem a seguinte apresentação:

\begin{abstract}
Nosso templo possui estrutura destinada a prover as necessidades da vida judaica, com comunhão nos Serviços Religiosos semanais aos Sábados, e atividades durante a semana, com palestras, aulas de conversão, e outros serviços que atendem aos interesses de nossa comunidade, mas também visa contemplar os simpatizantes da fé judaica, através do aprimoramento de estudos bíblicos, com a inserção de conceitos rabínicos e haláchicos.
\end{abstract}

Por acreditar que a conduta religiosa judaica é algo a ser constantemente aprimorada, cada membro de nossa comunidade tem sempre um canal aberto com a liderança, e por isso mesmo mantemos roshim (líderes) sempre à disposição, diariamente em nosso templo que, aptos a aconselhar e ensinar, de acordo com as tradições e do estilo de vida judaico, baseados na Torah e nos ensinos do Rav Yeshua, procuram servir à comunidade.

Nossos serviços religiosos possuem um rito devocional litúrgico acessível a todo o público, com as preces em hebraico, mas sempre oferecendo a tradução simultânea em projetores, para a perfeita compreensão de todos. Nossa adoração procura conduzir o povo no caminho da devoção e alegria, sem os quais a Shechinat HaShem (Presença Divina) não se faz presente no meio de nós.

Se você sente que no seu interior pulsa um coração judaico, que bate no ritmo da adoração sincera, no único objetivo de aproximar-se do Criador, a Congregação Israelita da Nova Aliança, espalhada em várias cidades pelo Brasil e exterior, te convida a visitar uma de nossas comunidades e sentir a Shechinat HaShem te tocar. (CINA, 2017a).

Segundo as informações disponibilizadas no site oficial da congregação (2017a), o rito litúrgico é acessível ao grande público, as preces são realizadas em hebraico, com a tradução em projetores. Creem no aperfeiçoamento dos membros da comunidade como demonstração da "Glória a Deus". Os líderes estão disponíveis nas sedes para prestarem auxílio religioso e outras informações, como as doações. Também possuem um canal oficial no YouTube intitulado “Ohel David”. 
O site se propõe a prestar diferentes serviços à comunidade e aos interessados na conversão, como a informação do horário para acender e apagar as velas do Shabat. No link "Departamentos" (CINA, 2017b) informam sobre o andamento da vida em grupo e suas lideranças, com as correspondentes tarefas de cada unidade:

\section{LIDERANÇA}

A nossa liderança é formada por homens que buscam viver uma vida de consagração e temor ao Eterno e suas mitsvot. Nosso colegiado de líderes é composto por homens que comandam suas kehilot nas diversas cidades do Brasil e exterior, que duas vezes no ano, reunem-se em nossa Sede Administrativa, em Curitiba/PR, para deliberarem a respeito de temas concernentes à nossa fé e prática.

Há uma diretoria administrativa que, nos intervalos das Assembléias gerais, toma as decisões no âmbito administrativo. Para os assuntos de tema religioso, nossa Congregação conta com um Beit Din Nacional (formado por sete líderes dos mais anciãos do povo) que formam o "tribunal rabínico", que funciona também como instância superior, em caso de eventual contestação de decisões tomadas por líderes locais.

\section{KOL HANASHI}

A voz feminina no povo Judeu se faz ouvir por meio de seu papel de representar a preservação de nossas tradições e valores familiares e religiosos. Esse projeto tem como proposta unir nossas mulheres em torno desse objetivo, com cursos e encontros onde questões de interesse feminino como shabat, pureza familiar e educação de filhos, entre outras, serão abordadas. Também possui diretoria própria, que trabalha sempre sob a supervisão dos roshim, líderes locais e do Beit Din Nacional.

\section{CHINUCH}

A palavra CHINUCH significa, em hebraico, transmissão, e refere-se ao processo de educação religiosa infantil, que se propõe à transmissão dos valores da fé judaica aos nossos filhos. Nossos voluntários levam isso como sua missão pessoal, ensinando hebraico, história de Israel e conceitos morais baseados na Torah e nas nossas tradições. A equipe desse departamento trabalha para, semanalmente, enviar material (por email) a líderes e professores da classe infantil em suas kehilot ministrarem as aulas de acordo com o conteúdo ensinado em nossa Sede, o Templo Ohel David, de Curitiba. (CINA, 2017b).

Como é possível perceber, a CINA é uma associação de indivíduos que se consideram convertidos ao judaísmo. Não apresenta rabinos nos seus quadros de lideranças religiosas, nem nos processos de conversão. Constitui-se como um grupo de judeus que optou pela adesão ao judaísmo sem a aprovação das instituições tradicionais judaicas. Assim, identifica-se com o que os dados do Censo de 2010 quantificaram: a multiplicidade de comportamentos religiosos no Brasil e o intenso trânsito entre os fieis, bem como a articulação crescente de novos grupos de crenças.

A CINA, matriz do grupo caxiense em estudo, não se insere no judaísmo tradicional, nem é aceita pelo mesmo. Mas elaborou uma percepção de judaísmo que vem atraindo fieis de diferentes regiões brasileiras. A estética judaica, utilizada pelos “israelitas de Curitiba”, atrai olhares e adeptos que, segundo o Censo de 2010, 
buscam por uma singularidade social da sua religiosidade. Chama a atenção, no site da CINA, a imponência de seu templo, diferentemente da instalação simples que abriga o grupo caxiense. Segundo esse site, toda a estrutura física, virtual e humana da comunidade demanda altos custos, o que remete à necessidade constante de receber doações. Informa que tudo o que a organização possui está atrelado ao trabalho voluntário e ao que é doado:

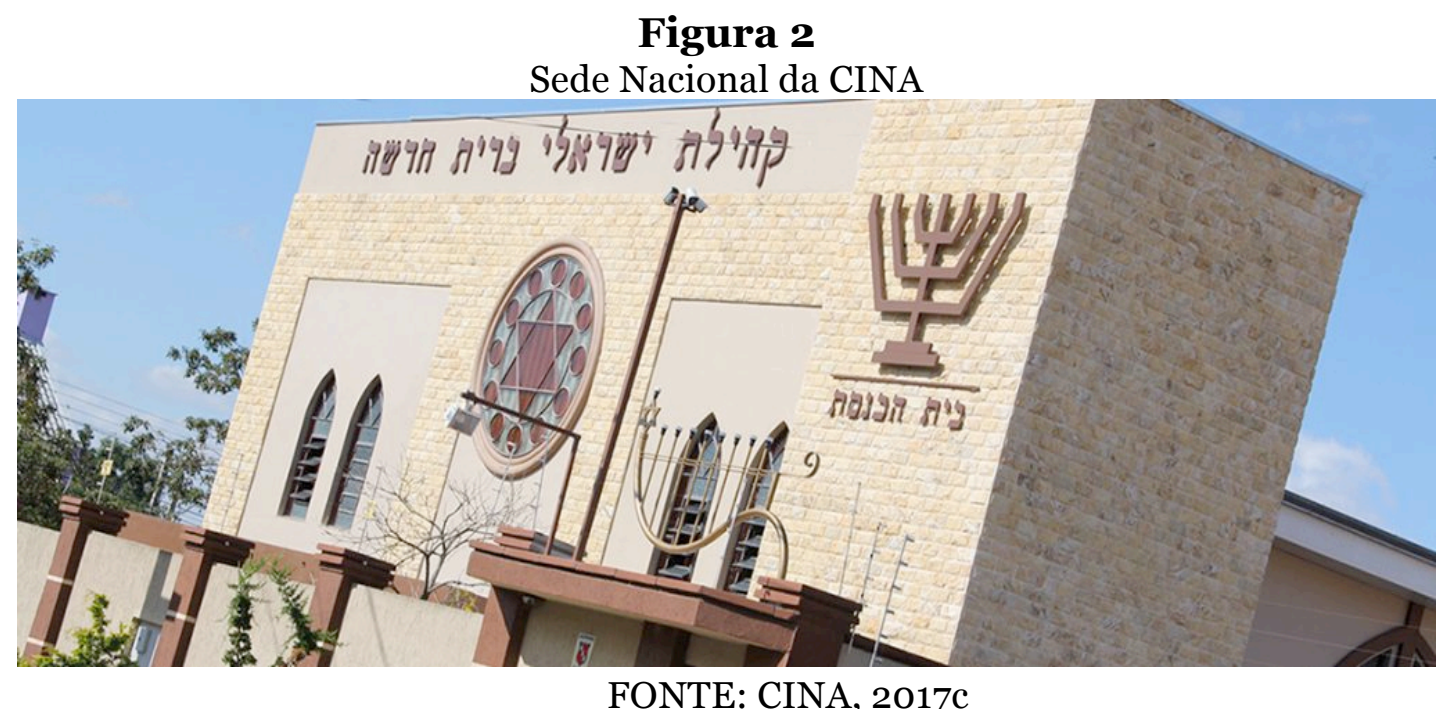

Apesar de apresentar uma instituição mais consolidada em termos materiais, a comunidade de Curitiba, segundo os depoentes da comunidade caxiense, apresenta um número pequeno de fieis. Acreditam que seja em torno de 50 participantes. E, apesar do proselitismo (condenado pelas correntes judaicas tradicionais), tem dificuldades em conquistar novos adeptos. Uma característica dos membros da CINA é serem "judeus" messiânicos, ou seja, aqueles que acreditam que Cristo é o messias, apenas questionam como a história do mesmo foi contada. Esse entendimento do judaísmo e seu conjunto de práticas são repassados para as demais extensões das comunidades que se organizam por meio da Congregação Israelita Nova Aliança.

Assim, a comunidade Nova Aliança de Caxias do Sul correspondia a uma extensão da CINA. Segundo um dos fundadores do grupo caxiense declarou ao jornal Pioneiro, em 2012, na época da fundação os "judeus" da cidade correspondiam a três ou quatro famílias que resolveram se encontrar em um mesmo espaço. Para obter permissão para fundar uma extensão da congregação na Serra Gaúcha, entraram em contato com a sede do grupo, que na época ficava em São Paulo, e pediram autorização.

A Congregação foi fundada em Caxias do Sul em 1981. Nas palavras dos depoentes $^{8}$, a busca pelo judaísmo se deu em função de uma tentativa de

8 Entrevistas concedidas à autora nos meses de junho e julho de 2017. Algumas vezes as falas dos depoentes aparecem em conjunto, pois a visão dos mesmos é uniforme sobre determinados aspectos 276 
aproximação maior com Deus. A religião judaica contemplaria necessidades que não estavam sendo atendidas em outras crenças, o que evidencia que esse novo contato religioso aconteceu por meio de um longo processo de migrações religiosas. Segundo a matéria do Jornal Pioneiro, a conversão foi um processo tranquilo para a maior parte dos integrantes da comunidade.

O processo também consistia em um rito simples; era necessária apenas uma entrevista manifestando o interesse, depois, de forma contínua, o indivíduo ia agregando conhecimentos sobre o judaísmo e suas práticas. No final, marcando o rito de passagem, o novo fiel passava por uma imersão na água (tevilá), como uma espécie de batismo. Segundo Sorj (1997), um processo de conversão é longo e demanda a aquisição de complexos conhecimentos, além do reconhecimento da intenção e posterior autorização de autoridades rabínicas. Também destaca a importância do processo de conversão se iniciar pela convivência com uma comunidade tradicional:

A preparação para a conversão implica basicamente na aquisição de conhecimentos judaicos. Cursos de história, tradições, cultura e língua hebraica com duração de nove meses ensinam a identificar certas manifestações coletivas da etnicidade judaica, como festividades, alguns rituais religiosos, a questão histórica do anti-semitismo, tradições culinárias, a importância do estado de Israel para os judeus, etc. (SORJ, 1997, p. 78).

Uma vez convertido nos moldes da Nova Aliança de Caxias do Sul, o fiel passava por um aprendizado religioso e por uma mudança de hábitos. O judaísmo do grupo deveria ser ostentado dentro de uma dinâmica que extrapolava o universo religioso. Por exemplo, exigia-se recato nas vestimentas, em especial, as femininas. O cumprimento rigoroso das regras do Shabat era outra exigência. A dieta alimentar também precisou passar por transformações. Apesar do grupo se constituir como judeus messiânicos, na perspectiva da CINA, no cotidiano, práticas das correntes mais ortodoxas do judaísmo foram incorporadas.

Percebe-se uma mescla do entendimento do judaísmo com denominações pentecostais. Muitos dos participantes eram egressos de comunidades evangélicas e deram continuidade às suas crenças e comportamentos vinculados à instituição considerada judaica. Além disso, nenhuma corrente específica da religião judaica era seguida pelo grupo, evidenciando atitudes ora reformistas, ora ortodoxas.

Dentro do templo, as mulheres vestiam trajes que remontam uma estética do início do século XX. Sentadas sempre à direita, segregadas dos homens, faziam dessas vestes uma espécie de roupa para a cerimônia religiosa, cuja inspiração deve ter vindo de imagens históricas das comunidades judaicas, evidenciando um confuso

da vida da comunidade em estudo. 
entendimento entre religiosidade e história do povo judeu. Também é possível perceber, por meio dos depoimentos dados ao jornal Pioneiro, que essa nova imagem pessoal também serviu de atrativo para vínculo com a Nova Aliança.

\section{Figura 3}

Mulheres na cerimônia religiosa na Congregação Nova Aliança de Caxias do Sul

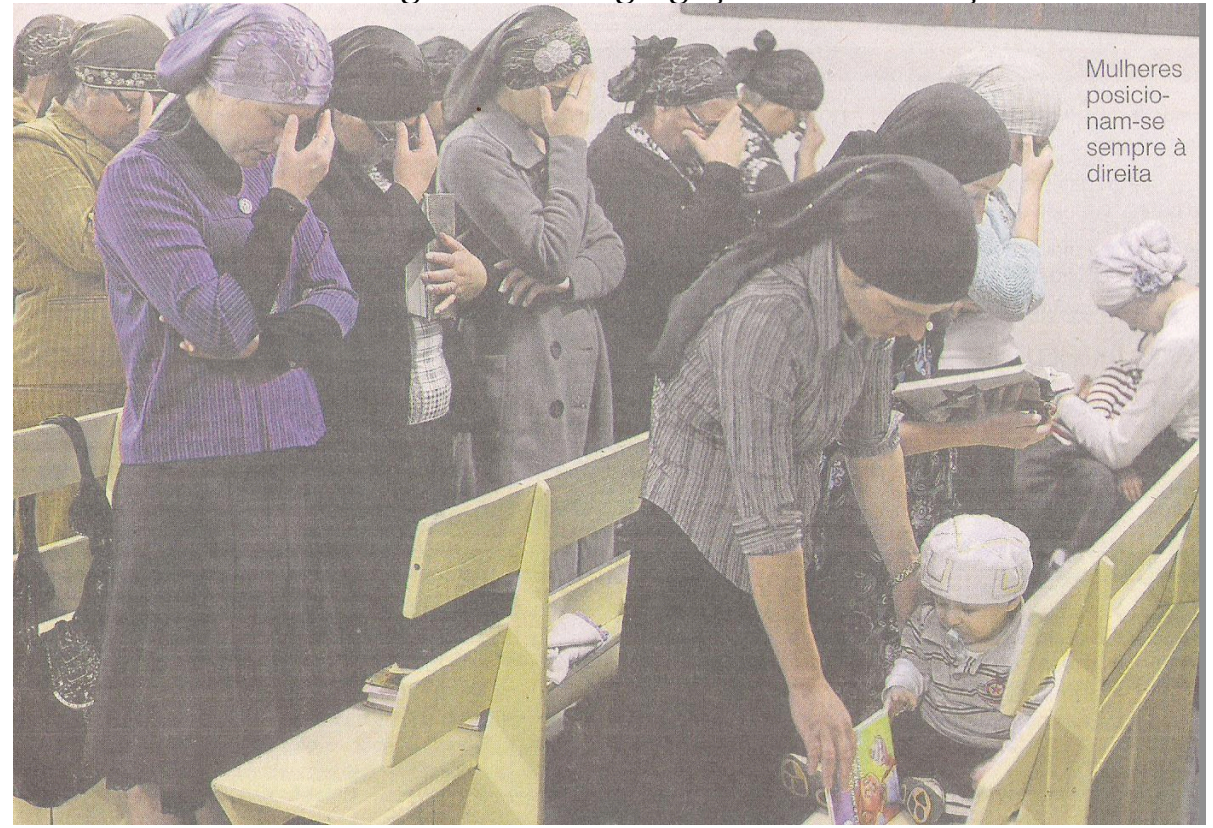

FONTE: Jornal Pioneiro, 4-5 fev. 2012, p. 04 (arquivo pessoal)

Sobre a ritualística do grupo, as cerimônias eram realizadas em uma casa simples, como já foi dito anteriormente, sem a estrutura de uma sinagoga. Não contava com a presença de um rabino, apenas com um líder, sem ascendência judaica, que coordenava todas as atividades da comunidade, conhecido na mesma por rosh Elazar Ben Elisha, cujo nome é Sérgio Boeira da Silva. Aliás, as trocas de nomes dentro da Nova Aliança foram frequentes. Nomes como Sara, Ester, Davi e outros foram adotados pelos fieis para serem utilizados dentro da congregação:

[...] os rituais que acontecem na beit seguem os costumes judaicos. Na sexta-feira, o shabat começa minutos antes do pôr do sol. A cerimônia leva pouco mais de uma hora e é embalada por cânticos. Em determinadas orações, o grupo dá as costas para o altar e vira para o Leste, em direção à porta e ponto do nascer do sol. É o momento em que todos se voltam a Israel. Nesse dia, é tocado o instrumento de sopro shofar, cujo som é equiparado à voz de Deus. Na sexta-feira acontece também a primeira das três refeições do Shabat. De forma simbólica, o rosh Elazar desce do altar e compartilha com todos pão e suco de uva ou vinho. No sábado, a cerimônia se encerra minutos após o pôr do sol. Geralmente, é Elazar quem comanda, mas ele incentiva outros a subir ao altar também, para que se formem mais líderes, e a comunidade prospere. (PIONEIRO, 4 e 5 fev. 2012, p. 04, arquivo pessoal). 
$\mathrm{Na}$ fala de três depoentes ${ }^{9}$, essa liturgia religiosa estava muito associada às denominações evangélicas das quais muitos fieis tinham feito parte. E esse sincretismo religioso teria promovido o fracasso da comunidade. Para os mesmos entrevistados, o que se fazia ali estava muito afastado do judaísmo; era essencialmente evangélico, frustrando os que realmente buscavam pela fé judaica.

A desestruturação da comunidade teria se iniciado cedo, mas agravou-se na segunda década do século XXI. Mesmo assim, em 15 de abril de 2014, quando a comunidade contava com aproximadamente 40 membros ${ }^{10}$, o jornal Pioneiro noticiou, em sua edição on line de 2014 (FRONZA, 2017), uma matéria intitulada Comunidade de Judeus em Caxias do Sul comemora Páscoa nesta terça-feira. Nesta, além de destacar a comemoração do calendário judaico em integração com a Catedral da cidade, uma série de afirmações foram feitas sobre a Nova Aliança e o judaísmo.

Aparece, na mesma edição, uma sessão denominada "Curiosidades", na qual diversos elementos religiosos do cristianismo (chamado apenas de catolicismo, na matéria) e do judaísmo aparecem listados. Além do título "Curiosidades" soar ofensivo por se tratar de um tema tão sensível para as comunidades religiosas, diversos equívocos são apresentados na matéria. No início da notícia, um subtítulo vago chama a atenção: Para a religião, Páscoa significa libertação do povo judeu enquanto escravo (FRONZA, 2017), sem determinar para qual religião, nem o local de escravidão.

Chama ainda a atenção o parágrafo que antecede uma imagem dos fieis da comunidade em uma festa da congregação. Eis o texto:

Em Caxias, os judeus se encontram sempre aos sábados na Congregação Israelita da Nova Aliança. A sede da congregação, chamada de beit, é uma modesta casa no bairro Serrano. O cenário, no entanto, parece acontecer em uma mesquita de Israel ou em qualquer outro ponto do Oriente Médio: cânticos e preces em hebraico, vestimentas típicas e distinção entre homens e mulheres. (FRONZA, 2017).

\footnotetext{
9 Entrevistas concedidas à autora nos meses de junho e julho de 2017.

$10 \mathrm{O}$ número de membros da comunidade foi, em geral, em torno de 50 pessoas, vivenciando um pico de 60 adeptos em um momento de ápice do grupo.
} 


\section{Figura 4}

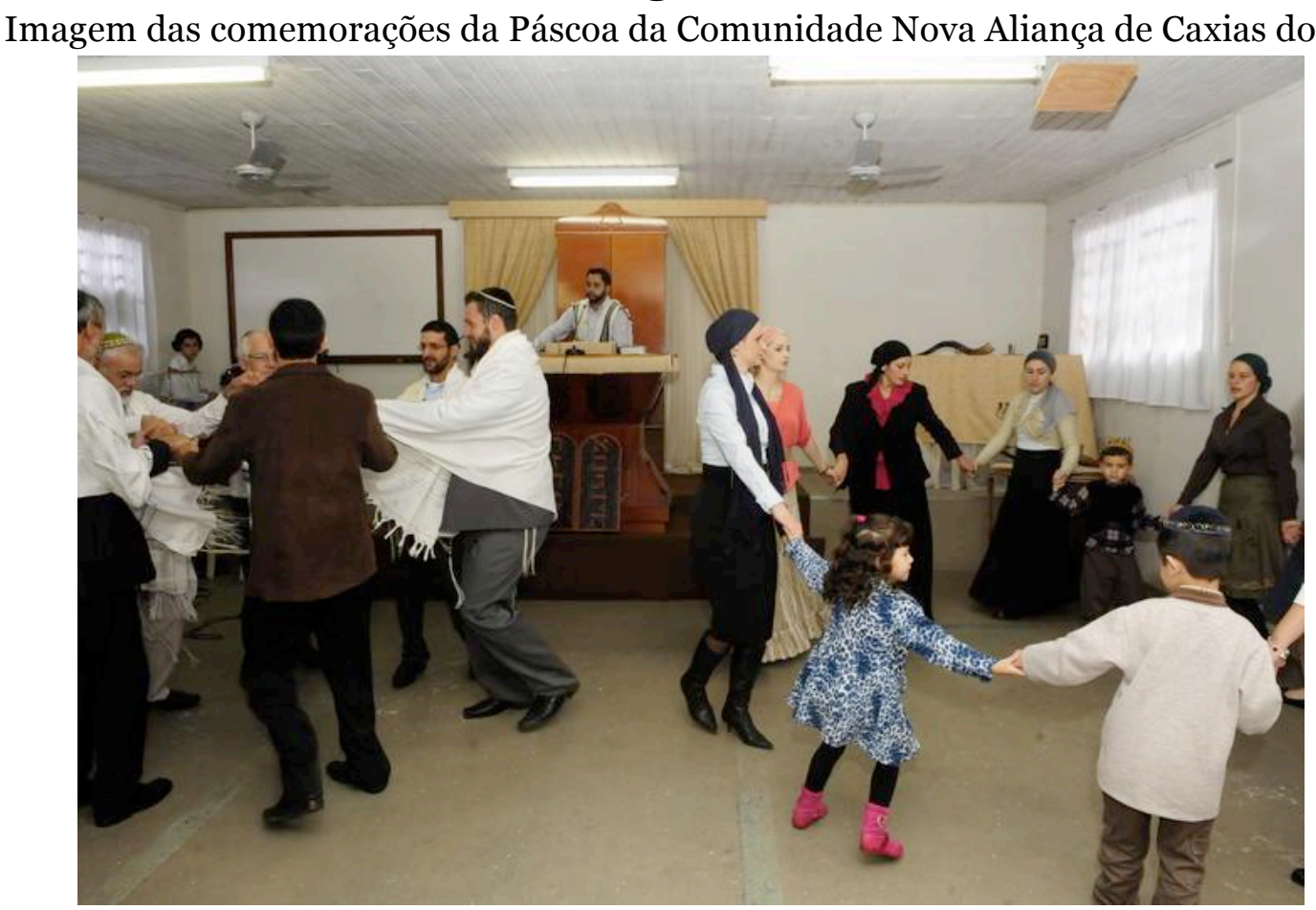

FONTE: FRONZA, 2017

Além da imagem não retratar nenhuma sinagoga, nem mesmo de forma frágil, espanta a falta de conhecimento sobre o judaísmo expressa na matéria. Mesquita é o templo religioso dos muçulmanos. Por que a cena lembraria qualquer região do Oriente Médio, já que, com exceção de Israel, os demais países da região são de maioria muçulmana e expressam forte antissemitismo? Nessa mesma matéria, o líder do grupo dos judeus da Nova Aliança, Elazar Ben Elisha, declara que as pessoas não têm a mínima noção sobre o que é o judaísmo. Torna-se necessário concordar com o líder, visto que nem mesmo a imprensa tem um mínimo conhecimento sobre o assunto.

Desprovidos de interlocutores privilegiados e orientações, os membros da congregação Nova Aliança se desarticularam em 2015. A instituição deixou de funcionar e seus fieis buscaram acolhida em outras correntes religiosas, ligadas ou não ao judaísmo. Um grupo constituiu uma extensão da organização na cidade de Vacaria, no Rio Grande do Sul, enquanto outros fundaram, em Caxias do Sul, uma nova organização que, acreditam, está mais ligada ao judaísmo tradicional.

\section{CONSIDERAÇÕES FINAIS}

O ano de 2015 marcou o fim da trajetória da Congregação Israelita Nova Aliança na cidade de Caxias do Sul. Alicerçada sobre influência cristã, com correntes católicas, protestantes e pentecostais, fragilizou-se diante do entendimento do 
judaísmo histórico e religioso. Um dos entrevistados declarou que o grupo iniciou suas atividades em 1975, "como uma igreja evangélica que em 2004 passou a adotar parte de ensinamentos, costumes e liturgia judaica, mas não podia ser caracterizada como uma instituição judaica por não seguir todos os ensinamentos da religião judaica" ${ }^{11}$.

Outro depoente 12 menciona o descontentamento com as lideranças em Curitiba. Foi mencionada, por vários depoentes, a falta de esclarecimentos que a CINA tem sobre o judaísmo, bem como o desrespeito às comunidades judaicas, pois consideram que a organização do Paraná é composta por evangélicos que pesquisam sobre o judaísmo na internet e saem se dizendo judeus, sem nenhum reconhecimento de Israel.

Acredita-se que às frustrações pessoais dos integrantes soma-se a falta de diálogo com a comunidade caxiense, pois não eram compreendidos enquanto grupo religioso. Da mesma forma, não eram reconhecidos pelas instituições judaicas tradicionais. Esta experiência de encontro com a religiosidade judaica conduziu alguns antigos membros da Nova Aliança à busca por conversões nos moldes tradicionais, por meio de organizações reconhecidas por Israel.

Por outro lado, alguns membros continuam vinculados à Nova Aliança, na cidade de Vacaria e em outras pelo Brasil. A congregação de Curitiba mantém suas atividades, promovendo um modelo particular de compreensão de judaísmo, não reconhecido por nenhuma organização judaica. Na edição do jornal Pioneiro on line, de 03 de fevereiro de 2012 (FEDRIZZE, 2017), o rabino Mendel, de Porto Alegre, declarou, ao ser questionado sobre a legitimidade desses grupos de conversão, que quem não nasceu judeu precisa ter o reconhecimento de uma autoridade rabínica de Jerusalém para se converter. Esses grupos de conversão, então, vivenciam uma experiência marginal junto ao judaísmo e ao cristianismo, já que se reconhecem como messiânicos.

O impacto dessas comunidades, no entanto, não pode ser minimizado, no Brasil. A constante busca pelo encontro pleno com o criador ou com uma crença que atenda às necessidades místicas parece ser trajetória religiosa de uma parcela significativa da população brasileira. Os processos de migração religiosa, identificados pelo censo de 2010, são constantes e marcados pelo contato com um número variado de crenças. Um mesmo indivíduo experimenta fé em correntes monoteístas, de matriz africana, espírita e de diferentes naturezas místicas. Pode, inclusive, se manter nas mesmas, caracterizando uma dupla ou tripla religiosidade.

\footnotetext{
${ }^{11}$ Entrevista concedida à autora em maio de 2017.

${ }^{12}$ Entrevista concedida à autora em junho de 2017.
} 
Ainda é importante observar, sobre o comportamento religioso brasileiro, uma tendência conservadora. A busca pelo judaísmo evidencia um processo rumo às correntes religiosas menos liberais. A procura pelo fundamento das religiosidades, que, muitas vezes conduz cristãos à religião judaica, também precisa ser analisado por meio da pesquisa histórica.

\section{REFERÊNCIAS}

CINA. Quem somos. Disponível em:<http://www.israelitas.com.br/OhelDavid/ index.php/quem-somos/>. Acesso em: 23 set. 2017 a.

CINA. Departamentos. Disponível em:<http://www.israelitas.com.br/OhelDavid/ index.php/quem-somos/>. Acesso em: 23 set. $2017 \mathrm{~b}$.

CINA. Congressos. Disponível em: <http://www.israelitas.com.br/OhelDavid/index.php /congresso-2017/>. Acesso em: 23 set. 2017c.

COSTA, Cléria Botêlho da. Memórias compartilhadas: os contadores de história. In: COSTA, Cléria Botêlho da; MAGALHÃES, Nancy Alessio (Org.). Contar história, fazer História: história, cultura e memória. Brasília: Paralelo 15, 2001.

CROSSAN, John Dominic. Quem matou Jesus?: as raízes do anti-semitismo na história evangélica da morte de Jesus. Rio de Janeiro: Imago, 1995.

CUNHA, Manuela Carneiro da. Antropologia do Brasil: mito, história, etnicidade. 2 ed. São Paulo: Brasiliense, 1987.

ELMIR, Cláudio Pereira. As armadilhas de um jornal: algumas considerações metodológicas de seu uso para a pesquisa histórica. Cadernos PPG em História da UFRGS, Porto Alegre, EdUFRGS, no. 13, dez. 1995.

FEDRIZZI, Fernanda. Congregação Israelita da Nova Aliança, em Caxias, é tema de reportagem do Almanaque. Jornal Pioneiro. 03 fev. 2012. Disponível em: <http: //pioneiro.clicrbs.com.br/rs/noticia/2012/02/ congregação-israelita-da-nova-alianca-emcaxias-e-tema-de-reportagem-do-almanaque-3652702.html>. Acesso em: 25 set. 2017.

FRONZA, Raquel. Comunidade de Judeus em Caxias do Sul comemora Páscoa nesta terça-feira. In: Jornal Pioneiro. 15 abr. 2014. Disponível em: <http://pioneiro. clicrbs.com.br/rs/geral/cidades/ noticia/2014/o4/comunidade-de-judeus-em-caxias-do-sulcomemora-pascoa-nesta-terca-feira-4475448.html> . Acesso em: 26 set. 2017.

GRIN, Monica; GHERMAN, Michel. Judaísmo e o Censo de 2010. In: TEIXEIRA, Faustino; MENEZES, Renata (Org.). Religiões em movimento: o censo de 2010. Petrópolis: Vozes, 2013.

LIA, Cristine Fortes. Bons cidadãos: a comunidade judaica do Rio Grande do Sul durante o Estado Novo (1937-1945). Tese (Doutorado) - Programa de Pós-Graduação em História, Pontifícia Universidade Católica do Rio Grande do Sul, Porto Alegre, 2004.

LIA, Cristine Fortes; RADÜNZ, Roberto. Identidade religiosa e italianidade: conflitos entre os grupos cristãos no Sul do Brasil. In: FRASQUET, Ivana; ESCRIG, Josep; RENAU, Laura Martínez (Org.). Anais do XVIII Congreso AHILA: em los márgenes de la História Tradicional. Nuevas miradas de América Latina desde el siglo XXI. Valencia: Universidade de Valencia, 2017. 
MEIHY, José Carlos Sebe Bom; RIBEIRO, Suzana L. Salgado. Guia prático de história oral: para empresas, universidades, comunidades, famílias. São Paulo: Contexto, 2011.

MEIHY, José Carlos Sebe Bom, HOLANDA, Fabíola. História Oral: como fazer, como pensar. 2 ed. São Paulo: Contexto, 2017.

PIAZZETTA, Luiz Carlos B.. Colônias italianas no Rio Grande do Sul. Arquivos da La Piave FAINORS Federação Vêneta. 2014. Disponível em: <http://imigrantesitaliano semguapore.blogspot.com.br/>. Acesso em: 25 set. 2017.

PORTELLI, Alessandro. O que faz a história oral diferente. Projeto História. São Paulo, PUCSP, no. 14, 1997.

SCLIAR, Moacyr. Do Éden ao divã: humor judaico. São Paulo: Shalom, 1990a.

SCLIAR, Moacyr. Mito, Judaísmo, Literatura. In: SCHÜLLER, Donald; GOETTEMS, Míriam Barcelos (Org.). Mito ontem e hoje. Porto Alegre: UFRGS Editora, $1990 \mathrm{ob}$.

SIMON-NAHUM, Perrine. Ser judeu na França. In: PROST, Antoine; VICENT, Gérard (Org.). História da vida privada v. 5: da Primeira Guerra a nossos dias. São Paulo: Companhia das Letras, 1992.

SORJ, Bernardo. Sociabilidade brasileira e identidade judaica. In: SORJ, Bila (Org.). Identidades Judaicas no Brasil Contemporâneo. Rio de Janeiro: Imago, 1997.

SORJ, Bila. Conversões e casamentos "mistos": a produção de "novos Judeus" no Brasil. In: SORJ, Bila (Org.). Identidades judaicas no Brasil contemporâneo. Rio de Janeiro: Imago, 1997.

WIESEL, Elie. O Golem: a história de uma lenda. Rio de Janeiro: Imago, 1986. 